CASE REPORT

\title{
Tension pneumothorax complicating autologous "blood patch" pleurodesis
}

\section{P Williams, R Laing}

Thorax 2005;60:1066-1067. doi: 10.1136/thx.2004.027854

Autologous "blood patching" has been used successfully for the treatment of persistent air leak in patients with spontaneous secondary pneumothorax. The case history is presented of a 19 year old woman with cystic fibrosis who developed tension pneumothorax following this procedure, with rapid clinical deterioration until the obstruction was cleared. To avoid this potentially fatal complication we recommend that "blood patch" pleurodesis be performed only through large bore intercostal catheters, that blood is rapidly transferred into the catheter tubing, a sterile saline flush and full resuscitation equipment is available, and the operator is skilled in the management of tension pneumothorax.

A potentially life threatening complication of the autologous "blood patch" pleurodesis procedure performed for a case of secondary pneumothorax with persistent air leak is described.

\section{CASE REPORT}

A 19 year old woman with cystic fibrosis and advanced lung disease (forced expiratory volume in 1 second $0.85 \mathrm{l} ; 26 \%$ predicted) presented with a large right sided spontaneous pneumothorax. In line with the 2003 BTS guidelines, ${ }^{1}$ a 12 French $(2.6 \mathrm{~mm}$ internal diameter) intercostal catheter was inserted in the fifth intercostal space, mid axillary line, and connected to an underwater seal drain, resulting in re-expansion of the right lung. However, there was persistent air leak on coughing despite 10 days of conservative treatment including a sustained period of continuous suction at $25 \mathrm{~cm} \mathrm{H}_{2} \mathrm{O}$. At this time a CT scan of the thorax confirmed a small right sided pneumothorax and changes in keeping with advanced cystic fibrosis lung disease. Given the advanced lung disease and the possibility of future lung transplantation, we were reluctant to consider either surgical or chemical pleurodesis. After discussion with our transplant centre we elected to perform autologous "blood patching" as described by Dumire et al. ${ }^{2}$

On day 15 of the admission, $50 \mathrm{ml}$ of blood was aspirated from the antecubital fossa via an 18 gauge $(0.9 \mathrm{~mm}$ internal diameter) cannula, the catheter tubing was clamped distally, and the blood was injected through the self-sealing rubber tubing under sterile technique. The tubing was unclamped and suspended $60 \mathrm{~cm}$ above the patient for 2 hours to prevent blood drainage and then lowered. The patient was not willing to be attached to further continuous suction. Although the procedure went without complication, a moderate air leak persisted the following day.

Previous series have shown success following repeat procedures, ${ }^{2-4}$ with larger volumes of blood, ${ }^{5}$ and with suction. ${ }^{24}{ }^{6} \mathrm{We}$ therefore decided to repeat the procedure, aiming to instil $100 \mathrm{ml}$ of autologous blood and to apply suction after 2 hours of free drainage. Initially, $50 \mathrm{ml}$ of blood was aspirated from a peripherally inserted central catheter and injected into the clamped intercostal catheter. However, subsequent aspiration of blood was slower and the next $50 \mathrm{ml}$ took approximately 2 minutes to obtain. Towards the end of this second injection the patient started to develop breathlessness. The procedure was immediately aborted. Despite injecting $20 \mathrm{ml}$ of sterile normal saline into the catheter, the drain was no longer functioning and the patient developed rapidly increasing respiratory distress. A diagnosis of tension pneumothorax secondary to blood clot blocking the chest tubing was made and oxygen was immediately administered. A further $50 \mathrm{ml}$ of sterile normal saline was injected forcibly into the tubing which succeeded in clearing the obstruction and restoring function of the chest drain. There was immediate resolution of respiratory distress and a subsequent chest radiograph on suction showed the lung was re-expanded.

Due to the severe lung disease, both we and the patient were reluctant to proceed to surgical pleurodesis. After 71 days of conservative treatment the air leak stopped and the drain was successfully removed. There has been no recurrence of pneumothorax after 6 months of follow up.

\section{DISCUSSION}

Autologous "blood patching" has been described as a simple, inexpensive, and safe treatment for persistent air leak from secondary pneumothorax ${ }^{2-47}$ and following surgery, ${ }^{25}$ with success rates ranging from 59\% to $100 \%$ in published series. ${ }^{3-5} 7$ It has proved to be successful even in cases where the lung is not re-expanded. ${ }^{4}{ }^{6}$ The only serious complication described in the literature is empyema which, although thought to be rare by some authors, affected three of 32 patients $(9 \%)$ in one series. ${ }^{7}$ With regard to the methods used for "blood patch" pleurodesis, there is little or no mention of the tube size used in these case series, although it is important to note that they were probably large bore.

Tension pneumothorax has, to our knowledge, never been described previously with this procedure, although the possibility was raised in a letter by Shackcloth et al. ${ }^{8}$ In patients with existing lung disease the deterioration can be very rapid due to lack of respiratory reserve, as was the case with our patient. We believe several factors contributed to catheter obstruction in this case. The use of a small bore catheter, prior instillation of blood during the first procedure, and slow venesection are all likely to have contributed to blood clot formation within the catheter and subsequent tension pneumothorax.

Based on our own clinical experience and published case series, we believe autologous "blood patching" is a useful therapeutic option in a selected group of patients with pneumothorax and persistent air leak. However, it is important that clinicians undertaking this procedure have an awareness of, take steps to avoid, and have the facility to deal with the potentially life threatening complication of tension pneumothorax. We recommend that (1) autologous "blood patching" be performed through large bore catheters only; (2) venesection from the patient be performed using $50 \mathrm{ml}$ syringes from an intravenous cannula ( $\leqslant 18$ gauge; $0.9 \mathrm{~mm}$ internal diameter) in an upper limb vein with rapid transfer of blood into the catheter tubing; (3) the catheter should be 
flushed with sterile saline after each injection of blood and a $50 \mathrm{ml}$ sterile saline flush should be available during the procedure to be used in the event of catheter obstruction; and (4) resuscitation equipment (including oxygen and pulse oximetry) should be to hand and the operator should be experienced in the management of tension pneumothorax with large bore cannulae and emergency chest drain insertion.

\section{Authors' affiliations}

P Williams, Department of Cardiology, Manchester Royal Infirmary, Manchester, UK

R Laing, Respiratory Services, Christchurch Hospital, Christchurch, New Zealand

The authors have no involvement in any organisation with a direct financial interest in the subject of the manuscript and no financial support was received for its preparation. There are no competing interests.

Correspondence to: Dr R Laing, Respiratory Services, Christchurch Hospital, Private Bag 4710, Christchurch, New Zealand; richard.laing@ cdhb.govt.nz
Received 13 May 2004

Accepted 12 August 2004

\section{REFERENCES}

1 Henry M, Arnold T, Harvey J. BTS guidelines for the management of spontaneous pneumothorax. Thorax 2003;58(Suppl II):ii39-52.

2 Dumire R, Crabbe MM, Mappin FG, et al. Autologous "blood patch" pleurodesis for persistent pulmonary air leak. Chest 1992;101:64-6.

3 Robinson CL. Autologous blood for pleurodesis in recurrent and chronic spontaneous pneumothorax. Can J Surg 1987;30:428-9.

4 Ando M, Yamamoto M, Kitagawa C, et al. Autologous blood-patch pleurodesis for secondary spontaneous pneumothorax with persistent air leak. Respir Med 1999;93:432-4.

5 de Andrés JJ, Blanco S, de la Torre M. Postsurgical pleurodesis with autologous blood in patients with persistent air leak. Ann Thorac Surg 2000;70:270-2.

6 Mallen JK, Landis JN, Frankel KM. Autologous "blood patch" pleurodesis for persistent pulmonary air leak. Chest 1993;103:326-7.

7 Cagirici U, Sahin B, Cakan A, et al. Autologous blood-patch pleurodesis in spontaneous pneumothorax with persistent air leak. Scand Cardiovasc J 1998;32:75-8.

8 Shackcloth $M$, Poullis $M$, Page R. Autologous blood pleurodesis for treating persistent air leak after lung resection. Ann Thorac Surg 2001;71:1402-3.

\section{Clinical Evidence-Call for contributors}

Clinical Evidence is a regularly updated evidence-based journal available worldwide both as a paper version and on the internet. Clinical Evidence needs to recruit a number of new contributors. Contributors are healthcare professionals or epidemiologists with experience in evidence-based medicine and the ability to write in a concise and structured way.

Areas for which we are currently seeking contributors:

- Pregnancy and childbirth

- Endocrine disorders

- Palliative care

- Tropical diseases

We are also looking for contributors for existing topics. For full details on what these topics are please visit www.clinicalevidence.com/ceweb/contribute/index.jsp

However, we are always looking for others, so do not let this list discourage you.

Being a contributor involves:

- Selecting from a validated, screened search (performed by in-house Information Specialists) epidemiologically sound studies for inclusion.

- Documenting your decisions about which studies to include on an inclusion and exclusion form, which we keep on file.

- Writing the text to a highly structured template (about 1500-3000 words), using evidence from the final studies chosen, within 8-10 weeks of receiving the literature search.

- Working with Clinical Evidence editors to ensure that the final text meets epidemiological and style standards.

- Updating the text every 12 months using any new, sound evidence that becomes available. The Clinical Evidence in-house team will conduct the searches for contributors; your task is simply to filter out high quality studies and incorporate them in the existing text.

If you would like to become a contributor for Clinical Evidence or require more information about what this involves please send your contact details and a copy of your CV, clearly stating the clinical area you are interested in, to CECommissioning@bmigroup.com.

\section{Call for peer reviewers}

Clinical Evidence also needs to recruit a number of new peer reviewers specifically with an interest in the clinical areas stated above, and also others related to general practice. Peer reviewers are healthcare professionals or epidemiologists with experience in evidence-based medicine. As a peer reviewer you would be asked for your views on the clinical relevance, validity, and accessibility of specific topics within the journal, and their usefulness to the intended audience (international generalists and healthcare professionals, possibly with limited statistical knowledge). Topics are usually 1500-3000 words in length and we would ask you to review between 2-5 topics per year. The peer review process takes place throughout the year, and out turnaround time for each review is ideally 10-14 days. If you are interested in becoming a peer reviewer for Clinical Evidence, please complete the peer review questionnaire at www.clinicalevidence.com/ceweb/contribute/peerreviewer.jsp 